\title{
Alkaline Phosphatase-Mimicking Peptide Nanofibers for Osteogenic Differentiation
}

\author{
Gulcihan Gulseren, ${ }^{\dagger}$ I. Ceren Yasa, ${ }^{\dagger}$ Oya Ustahuseyin, ${ }^{\dagger}$ E. Deniz Tekin, ${ }^{\ddagger}$ Ayse B. Tekinay, ${ }^{*}{ }^{\dagger}$ \\ and Mustafa O. Guler*, ${ }^{\dagger}$ \\ ${ }^{\dagger}$ Institute of Materials Science and Nanotechnology, National Nanotechnology Research Center (UNAM), Bilkent University, \\ Ankara, Turkey, 06800 \\ ${ }^{\ddagger}$ Faculty of Engineering, University of Turkish Aeronautical Association, Ankara, Turkey, 06790
}

\section{Supporting Information}

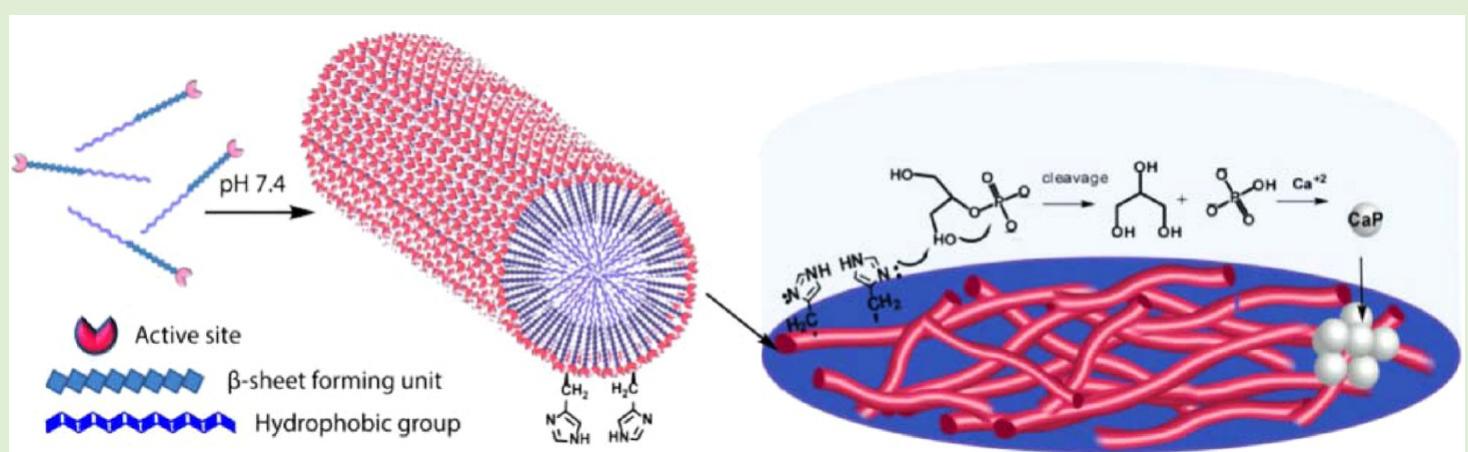

ABSTRACT: Recognition of molecules and regulation of extracellular matrix synthesis are some of the functions of enzymes in addition to their catalytic activity. While a diverse array of enzyme-like materials have been developed, these efforts have largely been confined to the imitation of the chemical structure and catalytic activity of the enzymes, and it is unclear whether enzymemimetic molecules can also be used to replicate the matrix-regulatory roles ordinarily performed by natural enzymes. Selfassembled peptide nanofibers can provide multifunctional enzyme-mimetic properties, as the active sequences of the target enzymes can be directly incorporated into the peptides. Here, we report enhanced bone regeneration efficiency through peptide nanofibers carrying both catalytic and matrix-regulatory functions of alkaline phosphatase, a versatile enzyme that plays a critical role in bone formation by regulating phosphate homeostasis and calcifiable bone matrix formation. Histidine presenting peptide nanostructures were developed to function as phosphatases. These molecules are able to catalyze phosphate hydrolysis and serve as bone-like nodule inducing scaffolds. Alkaline phosphatase-like peptide nanofibers enabled osteogenesis for both osteoblast-like and mesenchymal cell lines.

\section{INTRODUCTION}

Bone formation is a complex process, which requires coordinated action of several molecular and biological systems, ${ }^{1}$ and alkaline phosphatase (ALP) plays several roles in each level of this process. ALP increases the inorganic phosphate to pyrophosphate ratio $(\mathrm{Pi} / \mathrm{PPi})$ in the extracellular matrix through the nonspecific cleavage of phosphate esters. This action elevates the local concentration of inorganic phosphate, thereby promoting the formation of hydroxyapatite, which is an essential building block of bone tissue. ${ }^{2,3}$ In the preosseous cellular metabolism, ALP also shows osteoconductive and osteoinductive characteristics, which stem from its ability to induce osteoblast differentiation and to form a calcifiable bone matrix. ${ }^{4}$ The regulation of the bone matrix structure during mineral deposition is essential for the biomineralization process, and the importance of ALP in modulating the fine structure of newly deposited bone makes this enzyme a common target for bone regeneration studies. The ALP is yet to be considered as a model for peptide catalysis studies or nonpeptide artificial enzymes, although a macrocyclic tetramine complex has been reported as a mean to study its activity. ${ }^{5}$ ALP-based studies mostly utilize the native enzyme due to better catalytic efficiency, such as $k_{\text {cat }} / K_{\mathrm{m}}$ value of ALP is $2.4 \times$ $10^{7}$ for $p$-nitrophenyl phosphate (PNPP) substrate, ${ }^{6}$ whereas utilization of natural protein is costly to produce and it is susceptible to degradation. The immobilized native ALP is commonly used to produce ossification-inducing matrices in bone regeneration studies. ${ }^{7-9}$ Previously, fibrin scaffolds were exploited as enzyme-immobilizing system and the resulting complex was able to display catalytic and mineral inducing activities, as well as to accelerate osteoblast differentiation.? However, the effort and costs involved in enzyme purification

Received: May 1, 2015

Revised: June 1, 2015

Published: June 3, 2015 


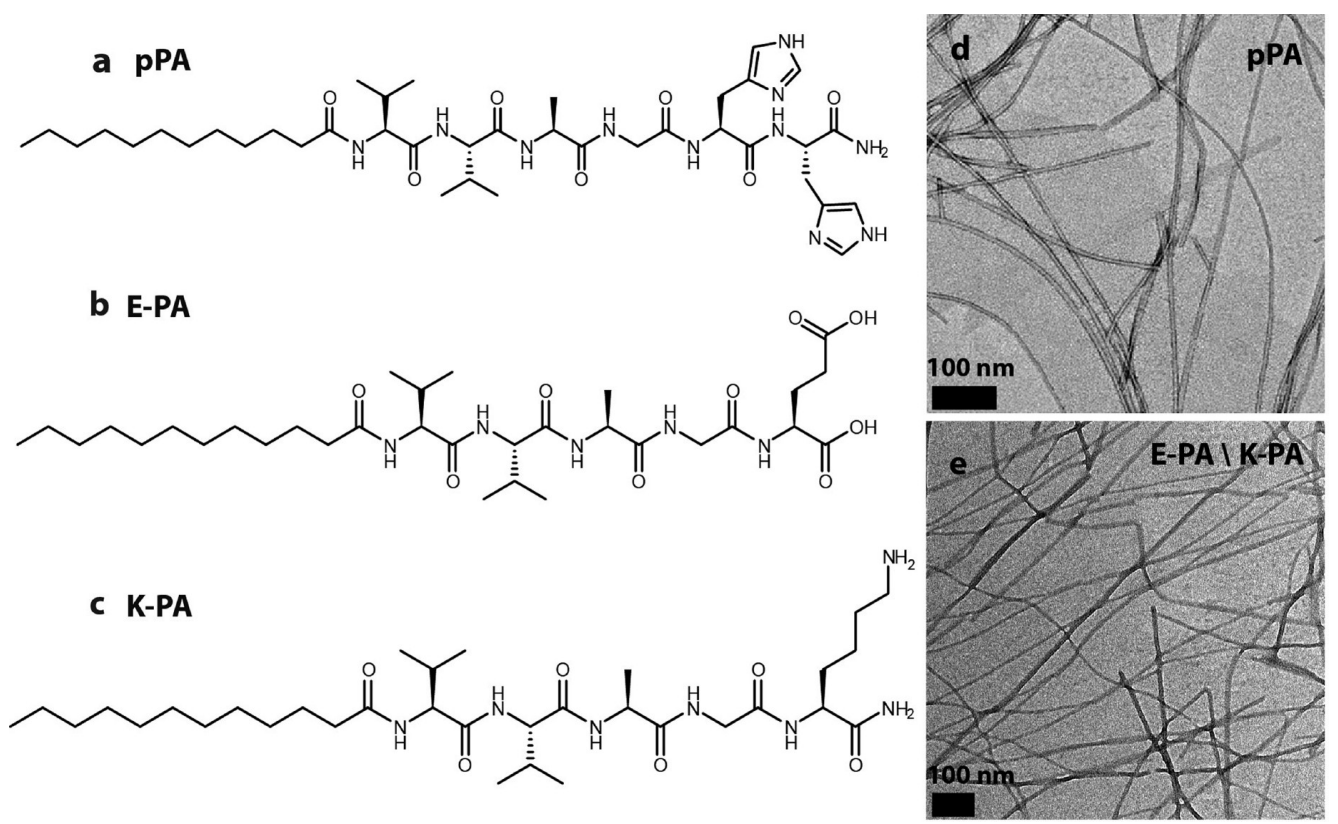

Figure 1. Chemical structures and TEM images of peptide amphiphile molecules. Chemical structure of (a) pPA (Lauryl-VVAGH-Am) and control group peptide amphiphiles: (b) E-PA (Lauryl-VVAGE) and (c) K-PA (Lauryl-VVAGK-Am). TEM images of (d) pPA and (e) E-PA\K-PA.

and handling, as well as the large batch-to-batch variances in bioactivity found in purified enzymes, precludes the widespread use of native enzymes in regenerative scaffolds. Therefore, investigation of artificial enzyme-like structures, designed by considering the active sites and biological roles of model enzymes, is crucial for the production of regenerationenhancing enzymatic scaffolds without isolation problems.

The catalytic activity of ALP depends strongly on imidazolecontaining histidine amino acids in the active domain. Imidazoyl moieties can play a diverse set of roles at physiological $\mathrm{pH}$. They behave as general bases or acids, or act as metal-aided nucleophiles to generate specific catalytic reactions. ${ }^{10}$ In ALP, histidine residues allow complexation of organophosphates onto the enzyme and facilitate the deprotonation of the water molecule, which is converted into an intermolecular nucleophile. This nucleophile subsequently attacks the ester bond of a phosphate monoester, initiating the hydroxyapatite mineralization process. ${ }^{3,11}$ In addition to their role in metalloenzymes, histidine residues in catalytic sites of nonmetalloenzymes are also known to display catalytic activity by themselves, due to the general acid/base characteristics of the imidazole group. ${ }^{10,12}$

Here, we show design of a bioactive peptide nanofiber, which has both the catalytic and biomineralization-enhancing functions of ALP, and displays a nanofibrous structure similar to that found in the native extracellular matrix. These artificial phosphatase-like peptide nanostructures (pPAs) possess catalytic centers that act as multifunctional nodules and can be used to produce bioactive, catalytic, and calcifiable bone matrix constructs. Peptide amphiphiles (PA) are an important class of molecules for bioinspired catalysis, owing to their ease of design and handling, presentation of multiple active epitopes, and potential for catalytic applications at physiological $\mathrm{pH}^{13-18}$ Here, we used peptide nanostructures as a scaffold for the enhancement of the biomineralization process facilitated through an enzyme-like catalytic activity created by the synergistic effects displayed between peptide molecules. Active sites of the individual peptide amphiphile molecules were decorated to present multiple histidine residues at the periphery of the nanofibrous system (Figure la and Supporting Information, Figure S1), where the residues are organized to achieve optimal cooperation and mimic the catalytic activity of the natural ALP enzyme. Furthermore, the synthetic ALPmimetic nanostructures induced efficient osteogenic differentiation of multiple cell types and facilitated the formation of bone-like nodules through the hydrolysis of organophosphate molecules on their surfaces.

\section{EXPERIMENTAL SECTION}

Peptide Synthesis. PA molecules (Supporting Information, Figure S1) were synthesized using 9-fluorenylmethoxycarbonyl (Fmoc) chemistry. Fmoc-protected amino acids, MBHA Rink Amide Resin, and HBTU (O-benzotriazole- $N, N, N, N^{\prime}$-tetramethyl-uroniumhexafluoro-phosphate) were purchased from Novabiochem, and lauric acid was purchased from Merck. A Fmoc-Glu- $(\mathrm{OtBu})$-Wang resin or Rink amide MBHA resin was used for peptide synthesis. For each coupling reaction, Fmoc groups were removed by shaking resins in $20 \%$ piperidine in $N, N$-dimethylformamide (DMF) for $20 \mathrm{~min}$. All amino acids were activated by adding 2 mol equiv of amino acid to 1.95 equiv of $O$-benzotriazole- $N, N, N^{\prime}, N^{\prime}$-tetramethyl-uronium-hexafluoro-phosphate (HBTU) and dissolved in $10 \mathrm{~mL}$ of DMF. After complete dissolution of the amino acid and HBTU in DMF, $3 \mathrm{~mol}$ equiv of $\mathrm{N}$-ethyl-diisopropylamine (DIEA) were added into the solution. Each coupling reaction was performed for $2.5 \mathrm{~h}$. Lauric acid was coupled to the peptide's N-terminal. Peptide cleavage and the removal of the protecting groups were performed with 95:2.5:2.5 trifluoroacetic acid (TFA)/triisopropylsilane (TIS)/water for $2.5 \mathrm{~h}$ at room temperature. TFA was rotary-evaporated. After evaporation, icecold diethyl ether was added and the solution was left at $-20{ }^{\circ} \mathrm{C}$ overnight. The pellet was collected and dissolved in deionized $\mathrm{H}_{2} \mathrm{O}$ and freeze-dried. After freeze-drying, peptides were dissolved in $1 \mathrm{mM}$ $\mathrm{HCl}$ solution in order to get rid of excess TFA, freeze-dried again, and were characterized by LC-MS.

Liquid Chromatography-Mass Spectrometry. An Agilent Technologies 6530 Accurate-Mass Q-TOF LC-MS equipped with a Zorbax SB-C8 column was used for LC-MS analysis. The concentration of the sample was $0.5 \mathrm{mg} / \mathrm{mL}$. The mobile phase was water $(0.1 \%$ formic acid for positive charged peptides, $0.1 \%$ ammonium hydroxide for negative charged peptides) and acetonitrile 
(0.1\% formic acid for positive charged peptides, $0.1 \%$ ammonium hydroxide for negative charged peptides). LC-MS was run for $25 \mathrm{~min}$ for each sample. Each run started with $2 \%$ acetonitrile and $98 \% \mathrm{H}_{2} \mathrm{O}$ for $5 \mathrm{~min}$, followed by the increase of the acetonitride gradient to $100 \%$ over $20 \mathrm{~min}$. Finally, acetonitrile concentration was decreased to $2 \%$ and the run was continued for a further $5 \mathrm{~min}$. The solvent flow rate was $0.65 \mathrm{~mL} / \mathrm{min}$. A total of $5 \mu \mathrm{L}$ of sample was injected for each run (Supporting Information, Figures S1-S3).

Transmission Electron Microscopy. A 1\% (w/v) peptide solution was prepared and alkalified with $0.1 \mathrm{M} \mathrm{NaOH}$ solution. The peptide gel was diluted with $1 \mathrm{mM} \mathrm{NaOH}$ and a small amount of solution was dropped to a carbon-covered copper grid. The $2 \%(\mathrm{w} / \mathrm{v})$ uranyl acetate solution was used to visualize the organic peptide fibers. The carbon grid was air-dried following staining. A FEI Tecnai G2 F30 transmission electron microscope was used to image the peptide amphiphile nanofibers (Figure 1).

Circular Dichroism. The secondary structures of peptide nanofibers ( $\mathrm{pPA}$ ) were analyzed with a JascoJ-815 circular dichroism spectrometer. A 1 wt \% peptide solution was prepared in $\mathrm{ddH}_{2} \mathrm{O}$ and jellified with $1 \mathrm{mM} \mathrm{NaOH}$. The peptide gel was then diluted with water and the circular dichroism (CD) spectrum of $1 \times 10^{-4} \mathrm{M}$ peptide solution was measured from 300 to $190 \mathrm{~nm}$ with 0.1 data pitch, $100 \mathrm{~nm} / \mathrm{min}$ scanning speed, $1 \mathrm{~nm}$ bandwidth, and 4 s D.I.T. The average of three measurements was used and sensitivity was selected as standard. Peaks indicating $\beta$-sheet presence were observed in the CD spectrum (Supporting Information, Figure S4).

Hydrolysis Kinetics Experiments. A $1.5 \times 10^{-4} \mathrm{M}$ pPA peptide solution was prepared at $\mathrm{pH} 8.0$. Peptide solutions were kept at $37^{\circ} \mathrm{C}$ for $30 \mathrm{~min}$ for fiber formation. Six different $p$-nitrophenyl phosphate (pNPP) substrate concentrations $(0.3-10 \mathrm{mM})$ were prepared in 25 $\mathrm{mM}$ Tris buffer at $\mathrm{pH}$ 8.0. A total of $50 \mu \mathrm{L}$ of substrate solutions were aliquoted in each well of a 96-well plate. Aliquots of $50 \mu \mathrm{L}$ of peptide solution were added into each well. Kinetic measurements were started immediately, and the absorbance spectrum of the resulting $p$ nitrophenyl (pNP) solution was collected at $405 \mathrm{~nm}$ with an extinction coefficient of $18600 \mathrm{M}^{-1} \mathrm{~cm}^{-1}$. Results were collected and calculated for each concentration and fitted into the MichaelisMenten equation (Figure 2).

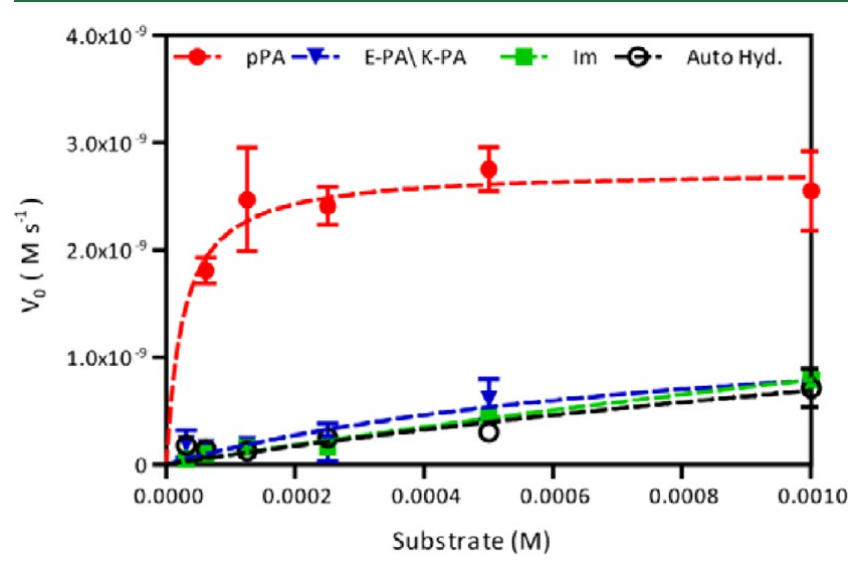

Figure 2. Michaelis-Menten diagram of the phosphatase activity of pPA, control E-PA $\backslash \mathrm{K}-\mathrm{PA}$ peptide nanofibers at $\mathrm{pH} 8$, and free imidazole $(\mathrm{Im})$ and autohydrolysis controls (error bars in all groups represent standard deviations of at least three independent measurements).

Theoretical Calculations. The pPA molecules were theoretically studied by a semiempirical molecular orbital method (called Parameterized Model-3 (PM3) ${ }^{19}$ with the Restricted Hartree-Fock $(\mathrm{RHF})^{20}$ formulation. After geometrical minimization, Single Point Energy (SPE) calculation using Density Functional Theory (DFT) ${ }^{21}$ with B3LYP (Becke, three-parameter, 22 Lee-Yang-Parr ${ }^{23,24}$ ) exchange-correlation potential was performed at the basis set 6$31 \mathrm{G}(\mathrm{d}){ }^{25}$ These calculations yielded the frontier molecular orbitals
(Highest Occupied Molecular Orbital (HOMO) and Lowest Unoccupied Molecular Orbital (LUMO)) and electrostatic potentials. The electrostatic potential maps of all four molecules were calculated to determine their chemical activity and electrostatic interactions with other molecules (Supporting Information, Figure S6). According to these maps, electron-accepting regions, plotted in blue, are on $\mathrm{C}$ atoms, which are double-bonded with the $\mathrm{O}$ atoms. The electrostatic charges on these $\mathrm{C}=\mathrm{O}$ bonds are between +0.57 and +0.64 for $\mathrm{pPa}$. Electron-donor regions (plotted in red) were found to be on the $\mathrm{N}$ atoms. For all molecules, the electrostatic charges in these regions range from -0.49 to -0.73 au.

CaP Mineralization. Glass coverslips were coated with $600 \mu \mathrm{M}$ peptide solution placed in 24-well plates. A total of $25 \mathrm{mM}$ Tris buffer at $\mathrm{pH}$ 7.4, supplemented with $24 \mathrm{mM} \mathrm{CaCl}_{2}$ and $14.4 \mathrm{mM} \beta$ glycerophosphate $(\beta$-gly $),{ }^{8}$ was added to each well to initiate the mineralization process. The solution was removed from the surface and coverslips were dried at ambient conditions prior to analysis.

Ca Mineralization Quantification. pPA and glass bare surfaces were supplied with $24 \mathrm{mM} \mathrm{CaCl}_{2}$ and $14.4 \mathrm{mM} \beta$-gly solution. ${ }^{8}$ After incubation, the solution was discarded and the plate was washed with water and stained with Alizarin Red S for $20 \mathrm{~min}$. After staining, coatings were washed again with water. Alizarin Red-bound calcium was extracted using $10 \%(\mathrm{w} / \mathrm{v})$ cetylpyridinium chloride in $10 \mathrm{mM}$ sodium phosphate $(\mathrm{pH} 7)$ for 20 min at room temperature and the concentration of Alizarin-Red $S$ was determined by microplate reader by measuring the absorbance at $562 \mathrm{~nm}$.

Scanning Electron Microscopy. FEI Quanta 200 FEG environmental scanning electron microscope was used for the acquisition of SEM images. Coverslips were coated with $3 \mathrm{~nm} \mathrm{Au-Pd}$ prior to imaging. Image acquisition was performed under $10-15 \mathrm{kV}$ voltage. Mineralized surfaces were prepared with the method explained above.

Raman Spectroscopy. A WITec Alpha300S Scanning Near-field Optical Microscope equipped with a Raman module was used to characterize calcium phosphate crystals on pPA surfaces. A Nd:YAG $532 \mathrm{~nm}$ laser source was used in the experiments. The integration time was $0.53492 \mathrm{~s}$, and the number of accumulation was 50. For Raman spectral images, a $150 \mu \mathrm{m} \times 150 \mu \mathrm{m}$ area was scanned with 50 points per line and 50 lines per image. The scan speed was $10.610 \mathrm{~s} /$ line and the integration time was $0.2122 \mathrm{~s}$.

X-ray Diffractometry. The crystallographic structure of calcium phosphate crystals was evaluated with a PAN analytical X'Pert X-ray diffractometer using $\mathrm{Cu} \mathrm{K} \alpha$ radiation. Peptide-coated glass surfaces were prepared as described and measured without further modification. The rotation time was $16 \mathrm{~s}$, scan range was from $20^{\circ}$ to $70^{\circ}$, and step size was $0.0525^{\circ}$. The planes observed were (111) and (211) for all of the crystals formed on surfaces.

Hydrolysis Experiments on the Surface. Hydrolysis experiments on peptide-coated surfaces were performed in $25 \mathrm{mM}$ TRIS buffer at $\mathrm{pH}$ 7.4. The $20 \mathrm{mM}$ pNPP solutions were prepared in diethanolamine solution from pNPP kit and used for hydrolysis (Sigma). Reactions were catalyzed with $1 \mathrm{mM}$ PA coatings.

Cell Culture and Maintenance. SaOS-2 human osteosarcoma (ATCC HTB-85) cells and rat mesenchymal stem cells (rMSCs) (Invitrogen) were used for in vitro cell culture experiments on pPAcoated culture surfaces. All cells were cultured and propagated in 75 $\mathrm{cm}^{2}$ cell culture flasks using Dulbecco's Modified Eagle Serum (DMEM) supplemented with 10\% Fetal Bovine Serum (FBS), 1\% penicillin/streptomycin, and $2 \mathrm{mM}$ L-glutamine. Cells were grown at $37^{\circ} \mathrm{C}$ in a humidified chamber supplied with $5 \% \mathrm{CO}_{2}$. All experiments were carried out after $80-90 \%$ confluency was reached. rMSCs were cultured in $75 \mathrm{~cm}^{2}$ cell culture flasks with a seeding density of $3 \times 10^{3}$ cells $/ \mathrm{cm}^{2}$ using DMEM supplemented with $10 \%$ Fetal Bovine Serum (FBS), 1\% penicillin/streptomycin, and $2 \mathrm{mM}$ L-glutamine for all experiments. rMSCs were used at passage number 7.

Cell Viability Assays on Peptide-Coated Surfaces. Viability of SaOS-2 cells was analyzed on pPA-coated culture plate surfaces at 24 , 72 , and $144 \mathrm{~h}$. Cells were seeded onto pPA-coated tissue culture plate surfaces in DMEM supplemented with 10\% FBS, $2 \mathrm{mM}$ L-glutamine, and $1 \%$ penicillin/streptomycin at a density of $2 \times 10^{4} \mathrm{cells} / \mathrm{cm}^{2}$. After the required incubation times, the viability of the cells on pPA coated 
and control surfaces was quantified by Alamar Blue assay (Invitrogen) by measuring absorbance values at $570 \mathrm{~nm}$ (background absorbance at $600 \mathrm{~nm}$ ). The viability of cells on pPA coatings was normalized to that of cells on bare surfaces. The viability of the 3D cell culture with SaOS2 cells was evaluated using the same procedure as the $2 \mathrm{D}$ experiments detailed above. The only difference was that $5 \times 10^{5} \mathrm{cells} / \mathrm{cm}^{2}$ were encapsulated within $10 \mathrm{mM}$ pPA gels.

Viability of rMSCs was analyzed with both Alamar Blue assay (Invitrogen) and Live-Dead assay (Molecular Probes, Invitrogen) to observe live and dead cells. Cells were seeded on 96-well plates, incubated for 24 and $48 \mathrm{~h}$, and centrifuged at $2500 \mathrm{rpm}$ for $5 \mathrm{~min}$. Cells were then stained with $1 \mu \mathrm{M}$ calcein $\mathrm{AM}(n=4)$ and $2 \mu \mathrm{M}$ ethidium homodimer for $40 \mathrm{~min}$ in dark. Washing steps during the staining protocol were performed at $2500 \mathrm{rpm}$ for $2 \mathrm{~min}$ to prevent dead cells from being washed away. Stained cells were observed under fluorescence microscope.

In Vitro Biomineralization Assay. Biomineralization and calcium phosphate tests with SaOS-2 cells were carried out on $1 \mathrm{mM}$ pPAcoated well-plates. pPA was gelated with DMEM medium at $\mathrm{pH}$ 7.4. pPA nanofibers were formed on culture plate surfaces as described above and coated surfaces were first incubated at $37{ }^{\circ} \mathrm{C}$ to strengthen the gels. Coatings were then allowed to dry in a chemical hood overnight. Calcium deposition on the surfaces was measured on days 3 and 6 using Alizarin Red as a quantitative colorimetric staining method. Briefly, cells were fixed with ice-cold ethanol for $1 \mathrm{~h}$ and stained with $40 \mathrm{mM}$ Alizarin-Red $\mathrm{S}$ for $15 \mathrm{~min}$. After washing 4-5 times with double-distilled water to remove nonspecific Alizarin-Red binding, cells were imaged with optical microscope. Alizarin Redbound calcium extraction was performed by using $10 \%(\mathrm{w} / \mathrm{v})$ cetylpyridinium chloride in $10 \mathrm{mM}$ sodium phosphate $(\mathrm{pH}$ 7) for $20 \mathrm{~min}$ at room temperature and the concentration of Alizarin-Red $\mathrm{S}$ was determined by measuring the absorbance at $562 \mathrm{~nm}$. For Alizarin Red staining assay, SaOS-2 cells were seeded on 24-well plates at a density of $2 \times 10^{4}$ cells $/ \mathrm{cm}^{2}$ in DMEM with $10 \%$ FBS. Cells were cultured in 10\% FBS/DMEM until they reached $90-100 \%$ confluence, after which the medium was replaced with fresh osteogenic medium containing $10 \mathrm{mM} \beta$-gly, $0.2 \mathrm{mM}$ ascorbic acid, and $100 \mathrm{nM}$ dexamethasone in $10 \%$ FBS/DMEM. This medium was replenished every 3-4 days during the course of experiments. The DNA content of each set was controlled with DNA quantification assay to confirm cell number equality for each sample. The procedure of $3 \mathrm{D}$ culture calcium deposition was similar, except that $5 \times 10^{5} \mathrm{cells} / \mathrm{cm}^{2}$ were encapsulated within $10 \mathrm{mM}$ pPA gel, and the cells were fixed with ethanol and stained with Alizarin-Red S for 5 min after the incubation period.

Gene Expression Analysis. The gene expression profiles of cells during osteogenic differentiation were assessed by quantitative RTPCR (qRT-PCR) analysis. The expression profiles of RUNX2 and Col I were analyzed for SaOS-2 cells, while these of RUNX2, COL I and Osp were analyzed for rMSCs. Reaction conditions were briefly as follows: $58{ }^{\circ} \mathrm{C}$ for $5 \mathrm{~min}, 95^{\circ} \mathrm{C}$ for $5 \mathrm{~min}, 40$ cycles of $95^{\circ} \mathrm{C}$ for $15 \mathrm{~s}$, $60{ }^{\circ} \mathrm{C}$ for $30 \mathrm{~s}$, and $40{ }^{\circ} \mathrm{C}$ for $1 \mathrm{~min}$, followed by a melting curve to confirm product specificity. The reaction efficiencies for each primer set were evaluated with a standard curve using 5-fold serial dilutions of total RNA.

SaOS-2 cells were seeded at a density of $4 \times 10^{4}$ cells $/ \mathrm{cm}^{2}$ on peptide nanofibers and total RNA was isolated using TRIzol (Invitrogen) according to manufacturer's instructions. Yield and purity of extracted RNA were assessed by Nanodrop 2000 (Thermoscientific). Primer sequences were designed using Primer 3 software. cDNA synthesis from RNA and qRT-PCR were performed using SuperScript III Platinum SYBR Green One-Step qRT-PCR Kit (Invitrogen) according to manufacturer's instructions. Primary gene expression results were normalized to the expression level of GAPDH for the analysis of the expression data. A comparative cycle threshold method was used to analyze the results.

Immunocytochemistry Staining and Imaging. In order to analyze DMP-1 protein localization, rMSCs were seeded onto pPA coated surfaces and glass surface at a density of $1 \times 10^{4}$ cells $/ \mathrm{cm}^{2}$. After reaching confluence, cells were incubated for 7 days in maintenance medium supplemented with only $\beta$-gly. Medium was changed every 4 days. Cells were then fixed in $4 \%$ paraformaldehyde/ PBS for $10 \mathrm{~min}$ and permeabilized in $0.1 \%$ Triton X-100 for $15 \mathrm{~min}$. To reduce nonspecific binding, samples were incubated with $10 \%(\mathrm{w} /$ v) bovine serum albumin/PBS blocking reagent for $30 \mathrm{~min}$ and treated with $6.7 \mu \mathrm{g} / \mathrm{mL}$ DMP-1 primary antibody (Abcam) overnight at $4{ }^{\circ} \mathrm{C}$. Samples were then incubated with goat antirabbit secondary antibody (DyLight 488) at 1:300 dilution for $1 \mathrm{~h}$ at room temperature. Extensive washing with PBS was performed between each step. All samples were counterstained with $1 \mu \mathrm{M}$ TO-PRO-3 (Invitrogen) in PBS for $15 \mathrm{~min}$ at room temperature and mounted with Prolong Gold Antifade Reagent (Invitrogen). Negative controls were obtained by omitting primary antibody and incubating with $1 \%$ normal goat serum/PBS. Samples were imaged using confocal microscope (Zeiss LSM510).

Rheology Analysis of 3D Culture. The formation of network structure at $\mathrm{pH} 7.4$ with and without cells was studied by oscillatory rheology. An Anton Paar Physica RM301 Rheometer operating with a $12 \mathrm{~mm}$ parallel plate configuration was used to probe the structural gel properties of the cell culture pPA networks. Samples were prepared by mixing pPA solution with DMEM and DMEM containing cells, incubated for 6 days and moved on the lower stage of the rheometer. A gap distance of $0.5 \mathrm{~mm}$ was used with $10 \mathrm{rad} / \mathrm{s}$ angular frequency and $0.1 \%$ shear strain.

Statistical Analysis. All experiments were independently repeated at least twice, with at least four replicas for each experimental or control group in each independent assay. All quantitative results are expressed as mean \pm standard error of means (SEM). Statistical analyses were performed by one-way analysis of variance (ANOVA) or Student's test, whichever applicable. Significant differences were evaluated by the $P$-value; differences were considered statistically significant at $P<0.05$.

\section{RESULTS AND DISCUSSION}

Phosphatase-Like Nanostructure Formation, Characterization, and Catalytic Activity Assessment. The selfassembly capability of the pPA (Lauryl-VVAGH-Am) molecules allow the production of multivalent nanostructures with high epitope densities. The pPA molecule was designed to selfassemble into nanofibers with active sites presented at the periphery (Figure 1a), while a combination of the imidazolefree peptides E-PA (Lauryl-VVAGE) and K-PA (LaurylVVAGK-Am) were used as a control group (Figure $1 b, c)$. The negatively charged E-PA and positively charged K-PA peptides were mixed in order to obtain nonactive nanofibers that are formed by electrostatic interaction of oppositely charged peptides and lack the catalytic sites present in ALPmimetic peptide nanofibers. Following the synthesis and purification of peptide molecules, the effect of secondary structure formation on the self-assembled peptide nanofibers was investigated by circular dichroism (CD) spectroscopy (Supporting Information, Figure S1-4). Peptide nanofibers adapted the $\beta$-sheet conformation at neutral $\mathrm{pH}$. TEM imaging revealed that the PPA molecules self-assemble into nanofibers with diameters of about 5-10 nm (Figure 1d,e, Supporting Information, Figure S4).

The hydrolytic capacity of the ALP-mimetic pPA nanofiber system was studied by measuring the catalytic production of $p$ nitrophenol from $p$-nitrophenyl phosphate (pNPP). This process relies on a reaction initiated by histidine, which enhances the nucleophilicity of water through partial proton donation and converts it to a nucleophile to cleave a phosphate group from the monoester. Enzymatic saturation profiles of pPA was analyzed using Michaelis-Menten kinetics to study its hydrolytic behavior. The pPA nanofibers exhibited significant catalytic activity, with a $k_{\text {cat }}$ value of $1.83 \times 10^{-5} \mathrm{~s}^{-1}$, while the 

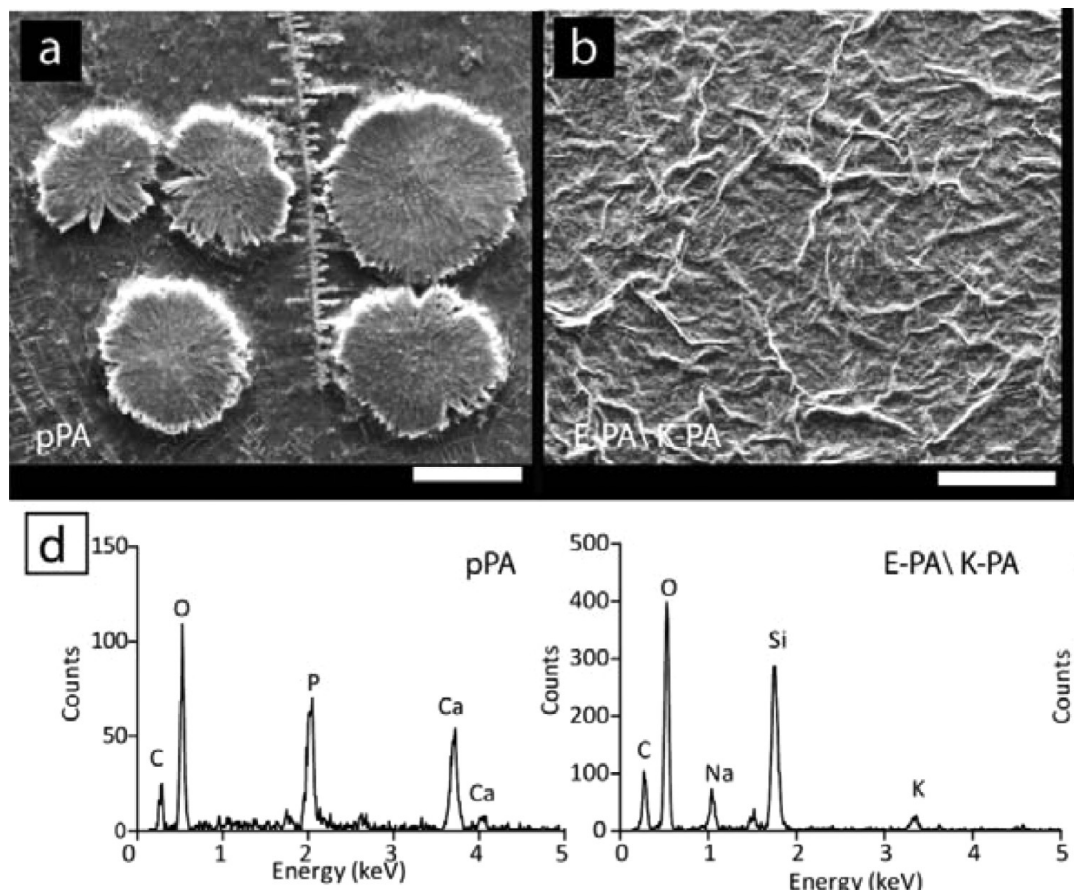

\section{C
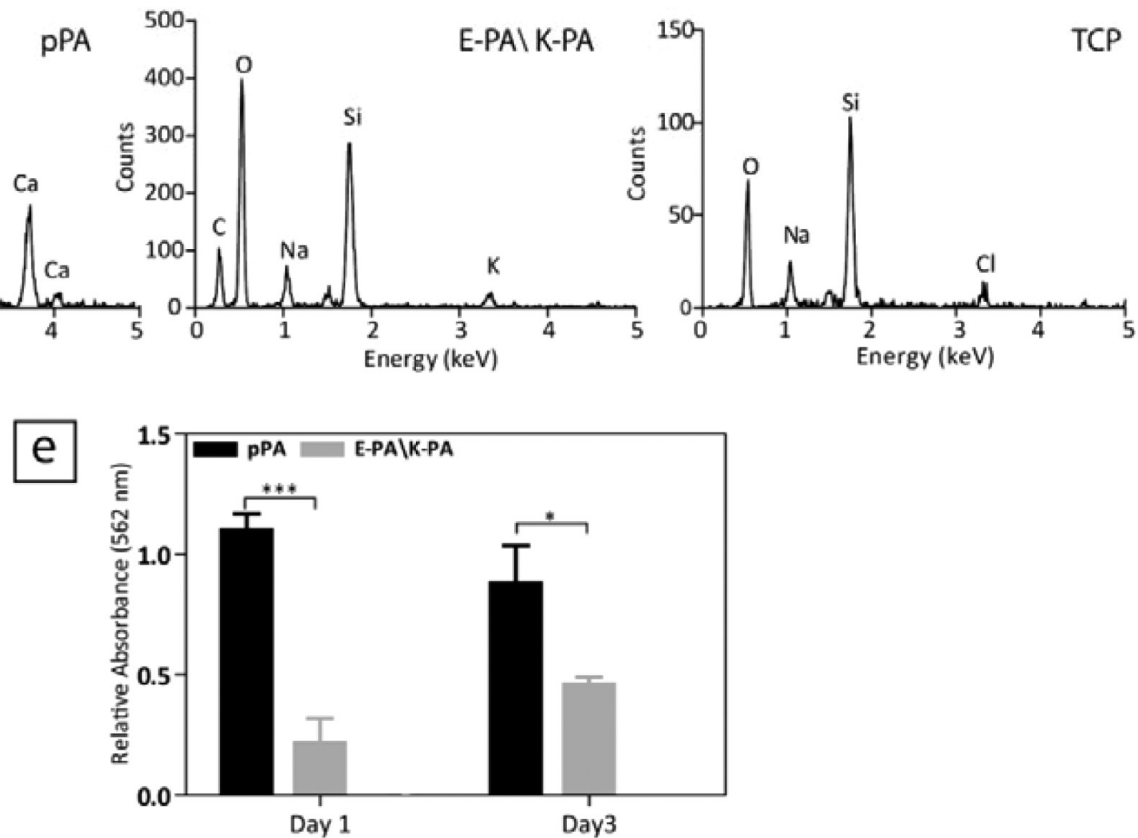

Figure 3. CaP deposition on pPA and E-PA \K-PA (imidazole-free control peptide group) coated surfaces. SEM images of the CaP nodules at day 1 on (a) pPA, (b) E-PA $\backslash K-P A$, and (c) uncoated tissue culture plate (TCP) surfaces (scale bars $=30 \mu \mathrm{m}$ ). (d) EDX analysis of mineral content on pPA, E-PA \K-PA, and TCP surfaces. (e) Calcium deposition analyses on surfaces at day 1, normalized to TCP. Statistical significance was determined by student $t$ test $(* p<0.05, * * p<0.01, * * * p<0.0001, n \geq 3$ assays $)$.

E-PA $\backslash$ K-PA combination showed slight activity, with a $k_{\text {obs }}$ of $6.87 \times 10^{-7} \mathrm{~s}^{-1}$ similar to free imidazole with $k_{\text {obs }}$ of $7.54 \times$ $10^{-7} \mathrm{~s}^{-1}$ (Figure 2, Supporting Information, Figure S5). Catalytic efficiency of the peptide nanofiber $\left(k_{\text {cat }} \backslash K_{\mathrm{m}}\right)$ was calculated as $0.69 \times 10^{-3}\left(\mathrm{M}^{-1} \mathrm{~s}^{-1}\right)$. This inherent catalytic activity of pPA could be derived from the positioning of two or more imidazoles in close proximity, which would generate an effective cooperation among the imidazole groups and encourage them to act as catalytic species. It is well-known that imidazole groups are involved in the catalytic mechanism of many enzymes, such as ribonuclease $\mathrm{A}$, and that they can be used as chemical catalysts, which play an essential role in the transesterification process through the deprotonation of the nucleophile as it attacks the carbonyl group. ${ }^{26}$ By taking advantage of these molecular properties of histidine, we were able to design an efficient PA structure that displays a remarkable catalysis rate with respect to free imidazole solution or imidazole-free peptide nanostructures.

The phosphate-cleavage reaction can occur through two kinetically indistinguishable pathways. In the first one, water molecules act as the nucleophilic group and are deprotonated by the concentrated general base activity of the imidazoles.
Alternatively, hydroxyl groups on $\beta$-glycerophosphate may be deprotonated by imidazole and generate nucleophiles, subsequently attacking the phosphoryl group of the substrate to cleave the phosphate ion. This mechanism is similar to the histidine-serine portion of the catalytic triad in serine proteases. $^{26}$ Free imidazole showed a much lower catalytic activity compared to peptide nanofibers, which illustrates the importance of histidine residue organization in the nanofibrous system (Figure 2). Preorganization of a supramolecular system containing high densities of histidine residues increases the efficiency of catalysis compared to free and dispersed imidazole. These results indicate that ALP-mimetic nanofibers display considerable catalytic activity against the organophosphate substrate compared to imidazole-free nanofibers and free imidazole molecules in the absence of a peptide template. The conclusion drawn from these results are in agreement with previous catalysis studies, ${ }^{10,13}$ which report that imidazole groups need to be presented in a specific conformation on the nanofibers in order to achieve catalytic activity. We also studied HOMO-LUMO locations and electrostatic potential mappings of the peptide molecules (Supporting Information, Figure S6a,b). As shown in Supporting Information, Figure S6, 

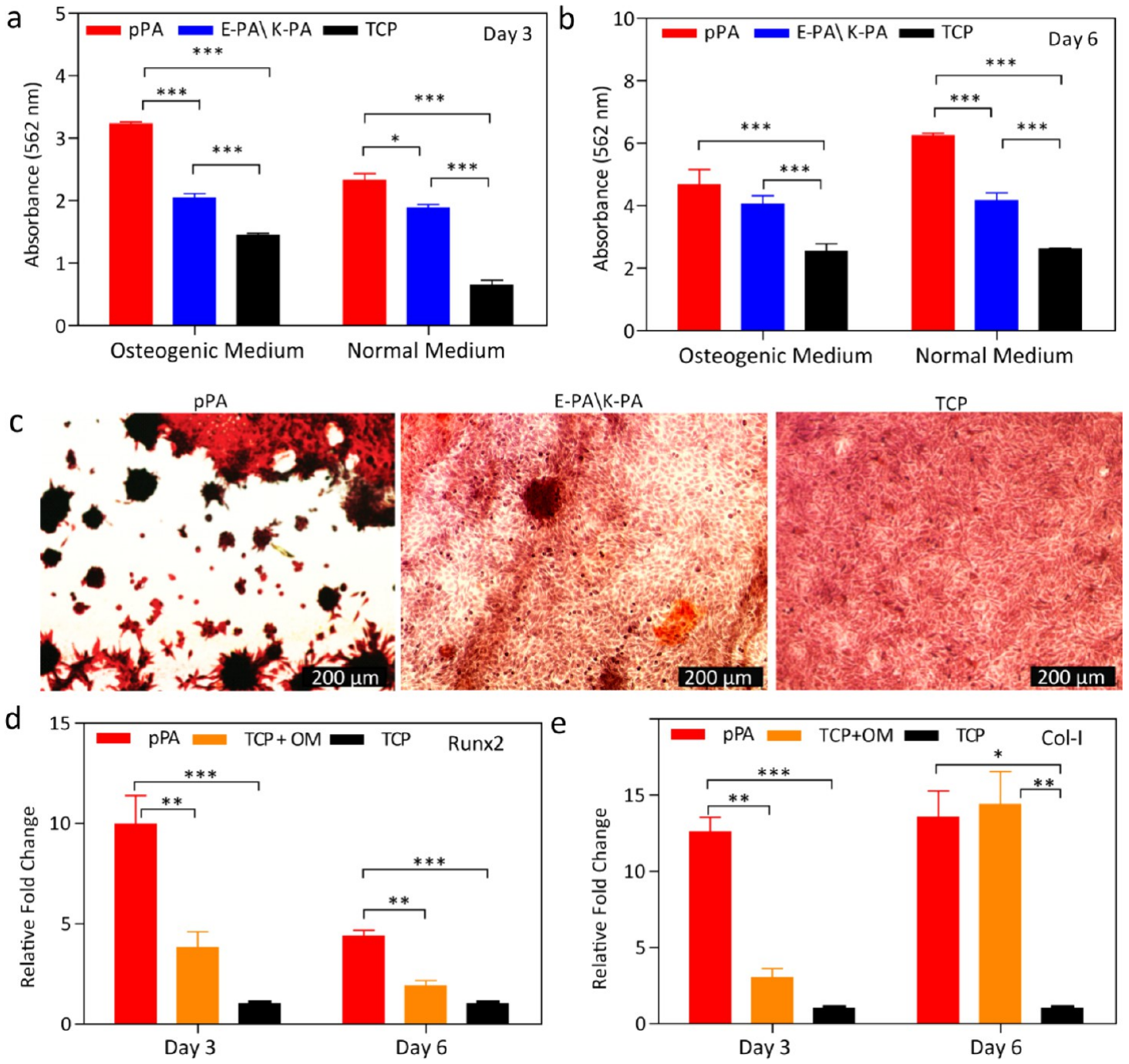

Figure 4. Analysis of calcium deposition and osteogenic marker gene expression levels. Quantitative analysis of calcium deposition on SaOS-2 cell cultured surfaces at (a) day 3 and (b) day 6 in osteogenic and normal culture medium. (c) Optical microscope images of Alizarin Red staining of samples in osteogenic medium at day 6. Gene expression analyses of (d) RUNX2 and (e) COL-I at both day 3 and day 6 in normal culture medium. Expressions were normalized to GAPDH and TCP $+\beta$-gly group (E-PA \K-PA denotes E-PA mixed with K-PA, TCP denotes the uncoated tissue culture plate, TCP + OM denotes the osteogenic medium-added uncoated tissue culture plate sample). Mean \pm SEM, $n=4$ coatings per sample, one-way analysis of variance (ANOVA); *p $<0.05, * * p<0.01, * * * p<0.0001$.

HOMO is mainly localized on one imidazole group and the LUMO is localized apart from the active site for the peptide molecules. The closer HOMO-LUMO regions contribute to the reactivity of the molecule as a result of the decrease in the energy required for the reaction. Therefore, the imidazole moieties are mainly responsive for the catalytic activity on the peptide molecules.

Mineralization on Catalytic Nanostructures. The ALP enzyme performs multiple functions during osteogenesis, providing a catalytic support for the initial formation of inorganic phosphate $(\mathrm{Pi})$ in addition to regulating the construction of calcifiable bone templates. ${ }^{27,28}$ In order to mimic ALP activity, it is important to replicate the effects of both of these processes. In a previous study, native ALP was immobilized on microporous fibrin scaffolds to promote biomineralization and bioactivity on fibrin surfaces. ${ }^{7}$ Similarly, we coated glass surfaces with phosphatase-mimicking peptide (pPA) to induce mineral formation. The $\beta$-sheet containing nanostructures have previously been utilized as templates for $\mathrm{CaP}$ mineralization, but the present study represents the first use of ALP-mimicking peptide nanofibers for induction of biomineralization. $^{29}$

The $\beta$-sheet containing nanofibers formed by the selfassembly of pPA molecules with catalytic activity were shown to provide an ideal platform to mimic both functions of the ALP enzyme. The analysis of biomineralization on ALPmimetic peptide nanofibers suggested that the pPA peptide nanofibers not only react with the substrate, but also serve as a suitable template for $\mathrm{CaP}$ crystal formation, similar to natural ALP (Figure 3, Supporting Information, Figure S7). The formation of $\mathrm{CaP}$ crystals on catalytic pPA nanofibrous surfaces was observed by Scanning Electron Microscopy (SEM) within $24 \mathrm{~h}$, while no mineralization was observed on imidazole-free peptide nanofibers (epitope-free E-PA and K-PA combination, E-PA $\backslash K P A$ ) or in the absence of peptides (Figure 3, Supporting Information, Figure S8). This result confirms the significance of imidazole groups presented on the peptide nanofibers for $\mathrm{CaP}$ deposition. The calcium content of the mineralized nodules found on peptide scaffold surfaces were also quantified through an Alizarin Red staining and cetylpyridinium chloride extraction 
and found to be significantly higher than nanofiber control and uncoated samples (Figure 3e).

Energy-dispersive X-ray (EDX) spectra analysis confirmed the presence of calcium $(\mathrm{Ca})$ and phosphate $(\mathrm{P})$ in mineralized nodules on pPA peptide nanofiber-coated surfaces (Figure $3 \mathrm{~d}$ ). Furthermore, X-ray diffraction (XRD) patterns of the $\mathrm{CaP}$ crystalline phases on peptide coatings correlated to the miller (hkl) indices (200) and (211) of hydroxyapatite (JSPDS Card No. 73-0293; Supporting Information, Figure S9). Raman spectral mapping was also utilized to visualize the $\mathrm{CaP}$ crystal formations, and revealed the presence of internal $\mathrm{PO}_{4}{ }^{3-}$ modes. In addition, Raman bands at 1430 and $1465 \mathrm{~cm}^{-1}$ could be attributed to the characteristic stretching modes of $\mathrm{CO}_{3}{ }^{2-}$ groups in hydroxyapatite ${ }^{30}$ (Supporting Information, Figures S10-11).

The hydrolytic capacity of PA nanofiber networks was also assessed on nanofiber-coated surfaces identical to those used in in vitro studies. These scaffolds also displayed strong catalytic activity and hydrolytic properties (Supporting Information, Figure S12). In addition, ALP-mimetic PA nanofibers serve as catalytic nucleation surfaces along their catalytic centers, and the activity of these multifunctional nanofibers results in the eventual saturation of the surface, thereby limiting Pi hydrolysis and $\mathrm{CaP}$ formation. Accumulation of $\mathrm{CaP}$ crystals on the surface therefore blocks the active sites present within the peptide network and gradually limits hydrolytic activity in a manner similar to the gradual decrease in activity observed in the natural enzyme, which is upregulated during osteogenesis and reduced toward the end of the biomineralization process. ${ }^{4}$ The catalytic saturation trend observed in our coating model is similar to the results associated with the soluble enzyme-like fiber system, suggesting that peptide-coated networks allow the fine regulation of free phosphate concentration and can be used for the controlled mineralization of two-dimensional environments.

Osteogenic Differentiation of SaOS-2 Cells on Catalytic Peptide Nanostructures. Formation of bone tissue is a complex process and involves multiple levels of hierarchical organization. ${ }^{1,3}$ Although there have been studies utilizing different extracellular matrix (ECM) mimicking peptide designs for bone regeneration, these studies focus on mimicking the specific signals incorporated with physical properties of ECM instead of directly regulating the mineralization process. ${ }^{31-35}$ However, the functional mimicry of the enzymatic components of the bone formation is also crucial for the development of regenerative scaffolds with multiple functionalities and the capacity to adequately stimulate the mineralization of osseous tissue.

ALP-inspired supramolecular nanostructures enhanced the biomineralization and osteodifferentiation of osteoblast-like SaOS-2 cells while supporting their viability (Supporting Information, Figure S13). These cells were observed to form bone-like nodules at as early as 3 and 6 days of culture on ALPmimetic peptide nanofiber coated surfaces. Both microscopic images and quantitative analysis by the cetylpyridinium chloride extraction of calcium showed that calcium deposition by SaOS2 cells was significantly enhanced compared to cells on tissue culture plate and peptide nanofibers without histidine residues (E-PA \K-PA), as evidenced by Alizarin Red staining of both osteogenic and normal culture media (Figure 4, Supporting Information, Figures S14 and S15). The osteogenic medium (OM) used was composed of $10 \mathrm{mM} \beta$-glycerophosphate, 0.2 $\mathrm{mM}$ ascorbic acid, and $100 \mathrm{nM}$ dexamethasone, while the normal medium was similar to maintenance medium, except with the addition of $10 \mathrm{mM} \beta$-glycerophosphate used as phosphate source. Osteogenic medium is commonly used in bone regeneration experiments and considered to be a necessary factor to direct cells into osteogenic differentiation; however, the performance of the pPA scaffold is exceptional in that the fibers were able to induce differentiation in the absence of other factors used as osteogenic supplements. The inclusion of an organic phosphate source was sufficient for bone nodule formation, which is a very strong indicator of the biomineralization-enhancing capacity of pPA nanofibers (Figure $4 a-c$ ). In addition to mineralization analysis, gene expression profiles of osteogenic differentiation markers were also analyzed by qRTPCR to further investigate the osteogenic differentiation process of the peptide networks. The efficiency of pPA nanostructures was compared to nonbioactive peptide nanofiber controls and evaluated with regards to their ability to induce differentiation without other osteogenesis-inducing factors. Statistically significant enhancements were observed in the expression of both Runt-related transcription factor-2 (RUNX2) and collagen type I (COL-I) on ALP-mimetic peptide nanofiber coated surfaces compared to control groups on both days 3 and 6 of culture, even in the absence of an osteogenic culture medium (Figure 4d,e). RUNX2 is an essential transcription factor that regulates the expression of specific genes, such as collagen I (COL-I), osteopontin (OSP), and bone sialoprotein (BSP), that are important for bone development. ${ }^{36-38}$ As such, the upregulation of RUNX2 in the early stages of culture suggests that the progenitor cells are undergoing or will undergo osteogenic differentiation. ${ }^{39}$ In accordance with the Alizarin Red S staining results, cells cultured on pPA nanofibers exhibited significantly higher expressions of RUNX2 following 6 days of incubation compared to control groups. It is striking that the expression of the late osteogenic differentiation marker COL-I was upregulated in cells cultured on pPA nanofibers on both day 3 and day 6 , whereas the osteogenic medium-supplemented control group on tissue culture plates only started to activate COL-I gene expression on day 6, similar to previous studies. ${ }^{35-40}$ Collagen $I$ is the main scaffold protein of the bone matrix and the expression of this protein is regulated by ALP during osteoblast formation and differentiation. As such, the scaffolding and catalytic activities of $\mathrm{pPA}$ nanostructures were able to accelerate the commitment of osteoblast-like cells into the osteogenic lineage by inducing the expression of osteogenic genes without the need of an osteogenic medium, as evidenced by both gene expression profiles and Alizarin Red staining.

Osteogenic Differentiation of Mesenchymal Stem Cells on Catalytic Peptide Nanostructures. Stem cells are commonly used in regenerative therapies and may play a key role in the artificial reconstruction of bone tissue through the enhancement of osteogenesis. As such, the effect of the pPA nanostructures on the osteogenic differentiation potential of mesenchymal stem cells (MSCs) was also determined to evaluate the possibility of using a combination of stem cells and peptide scaffolds for regenerative studies. However, the multilineage capacity of MSCs makes their use more challenging compared to osteoblast-like cells. The contents of osteogenic medium are crucial to direct the osteogenic differentiation of MSCs, as well as to prevent their differentiation into other cell fates. Similar to SaOS-2 results, ALPmimetic peptide nanostructures were found to be biocompat- 

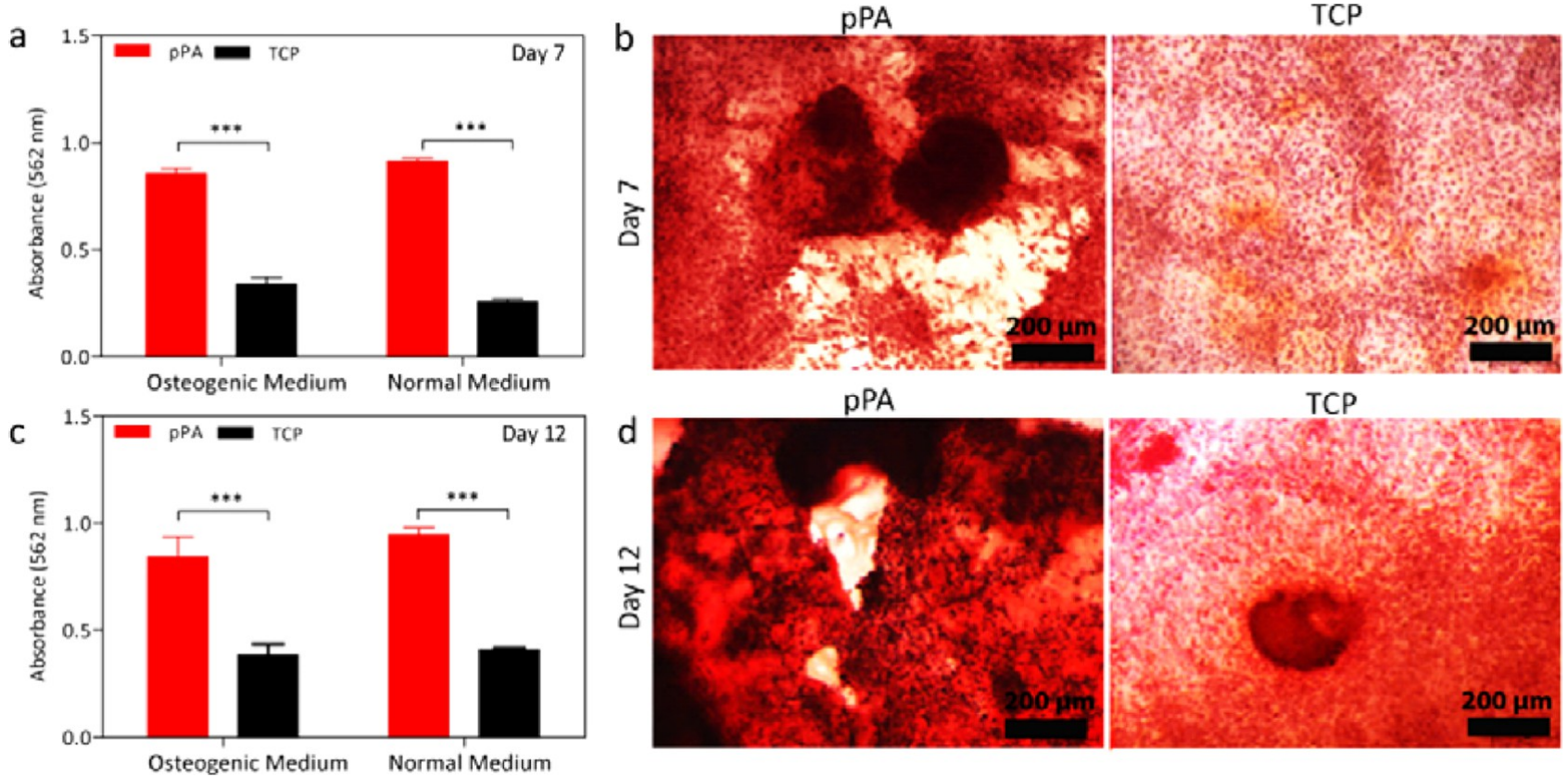

Figure 5. Quantitative analyses of calcium deposition on rMSC cultured surfaces at (a) day 7 and (c) day 12. Optical microscopy images of Alizarin Red staining of cells in the absence of osteogenic supplement at (b) day 7 and (d) day 12 (mean \pm SEM, $n=4$ coatings per sample, student $t$ test $(* p<0.05, * * p<0.01, * * * p<0.0001)$.
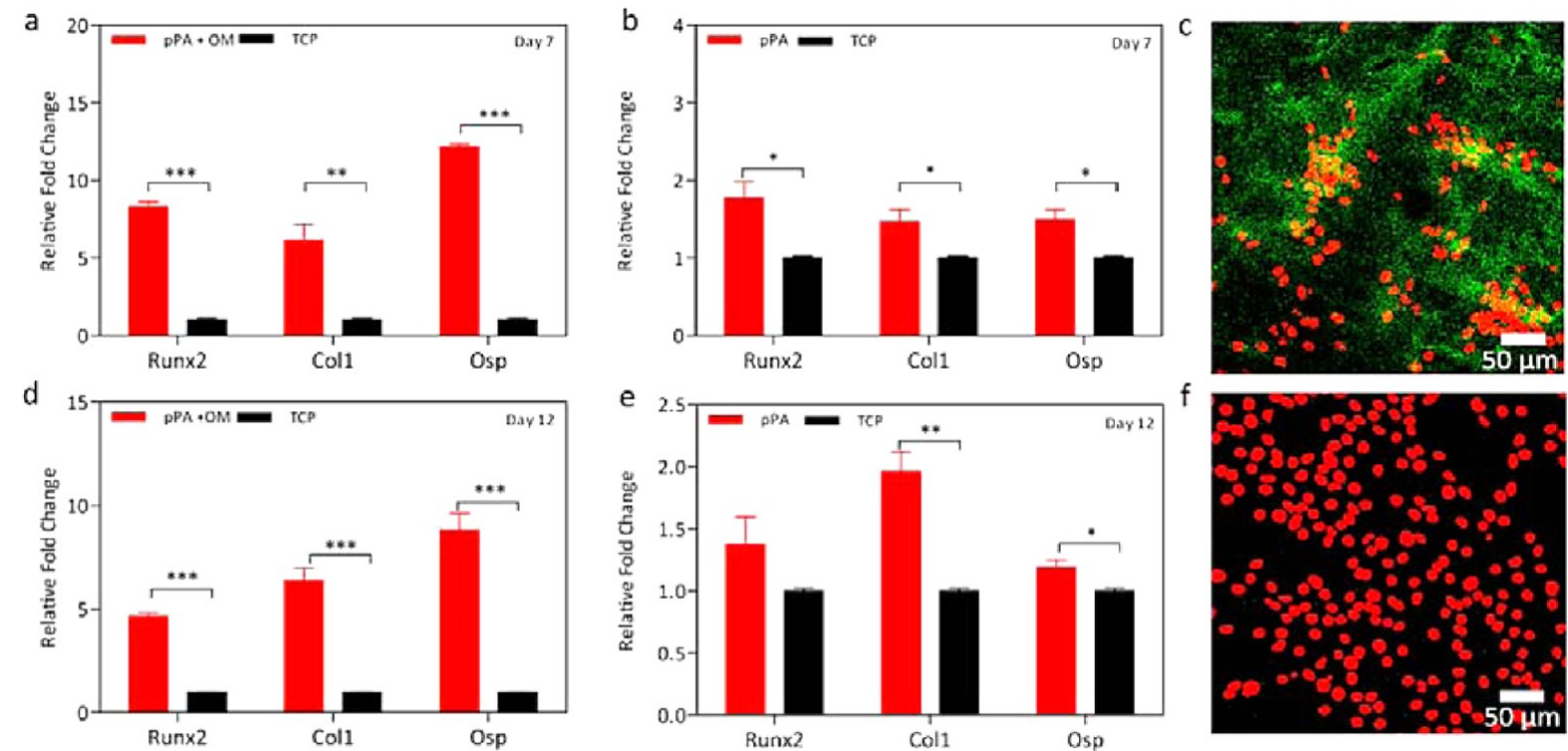

Figure 6. Gene expression analyses of Runx2, ColI, and Osp of rMSCs with qRT-PCR on (a) day 7 with pPA + osteogenic medium (pPA + OM), (b) day 7 with normal culture medium, (d) day 12 with pPA + osteogenic medium (pPA + OM), and (e) day 12 with normal culture medium. Expressions were normalized to GAPDH and nonosteogenic medium containing TCP control group. Confocal images of DMP-1 staining at day 7 (c) pPA, (f) TCP surface with normal culture medium (scale bar $50 \mu \mathrm{m}$; red fluorescence belongs to TO-PRO nucleus staining and green emission is DMP-1 staining; mean \pm SEM, $n=3$, and statistical significance was determined by Student's $t$ test $* P<0.05, * * P<0.01, * * * P<0.0001)$.

ible (Supporting Information, Figure S16) and induced biomineralization by MSCs to a significantly greater extent compared to bare surfaces, as evidenced by Alizarin Red staining (Figure 5, Supporting Information, Figure S17). Significant deposition of calcium could be observed at as early as day 3 and increased in subsequent days of culture (Supporting Information, Figure S18). Active site-free PAs (E$\mathrm{PA} \backslash \mathrm{K}-\mathrm{PA})$ were not included in differentiation experiments with mesenchymal stem cells, as networks of these peptides were found not to induce the osteogenic differentiation of osteoblast-like SaOS-2 cells as much as the pPA network did. We observed that $\mathrm{pPA}$ nanofibers accelerated the differentiation of rMSCs in only $\beta$-gly supplemented normal culture medium as effectively as cells incubated in osteogenic medium. This is a significant improvement over previous studies, which recorded that the differentiation of rMSCs to osteoblasts is possible only after long incubation periods (after 2 weeks) and in the presence of osteogenic supplements. ${ }^{41}$ In contrast, the pPA nanofibers initiated the osteogenic differentiation of MSCs within 3 days without any osteogenic support, and had 


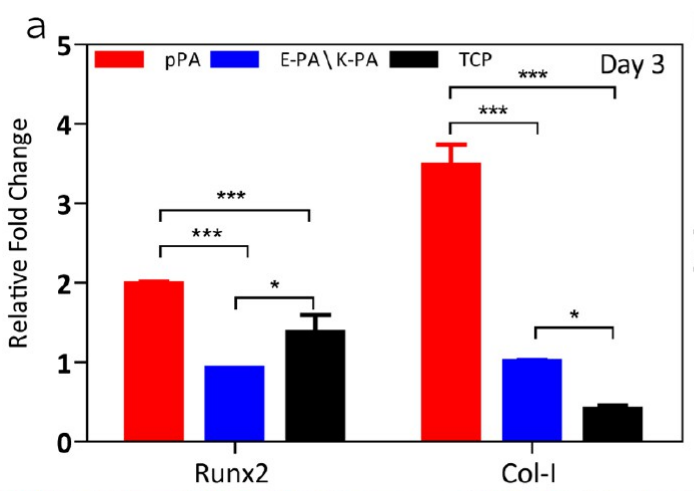

b
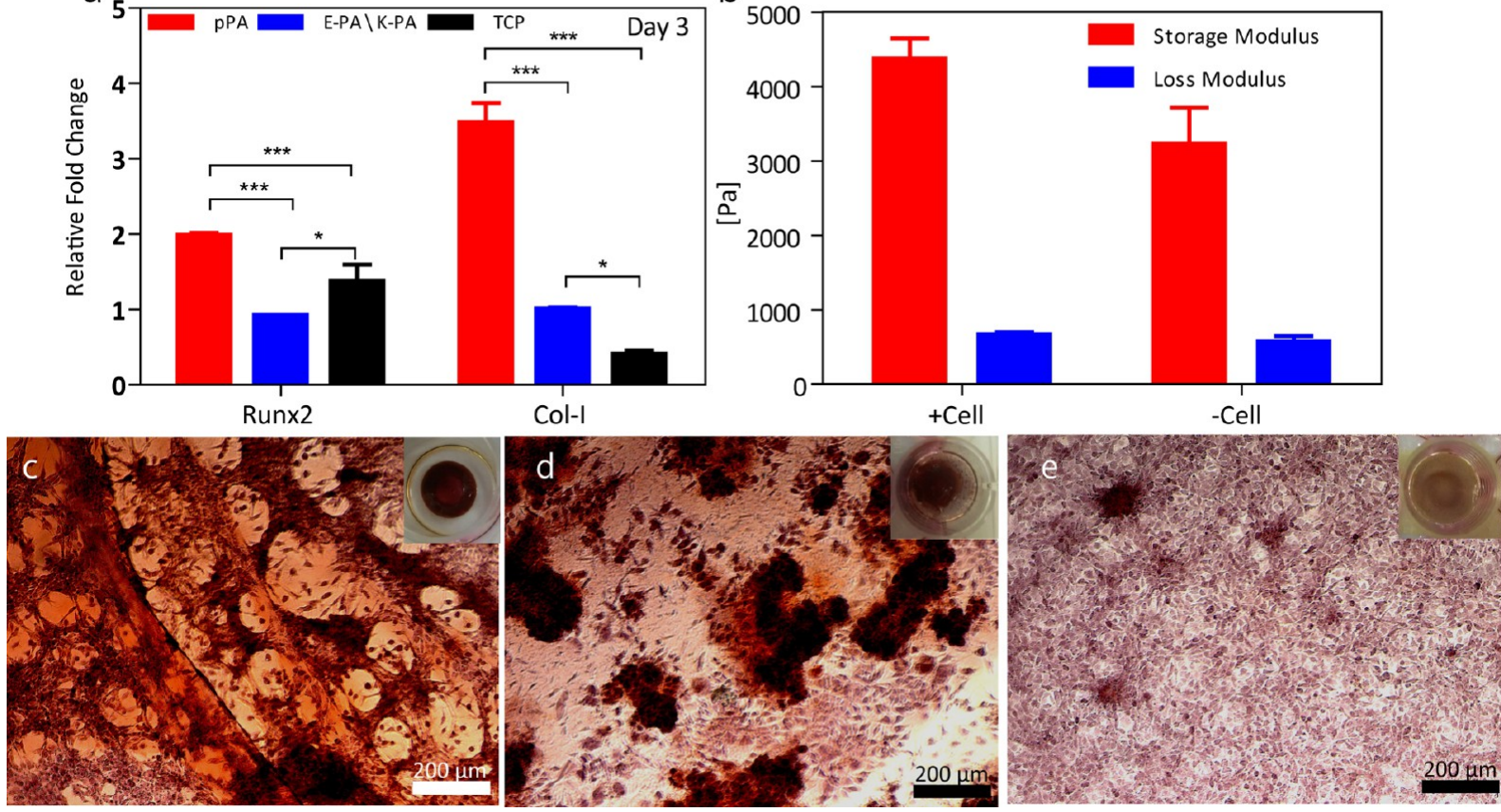

Figure 7. (a) Gene expression analysis of Runx 2 and ColI of SaOS-2 with in 3D qRT-PCR at day 3 with normal culture medium, expressions were normalized to GAPDH. (b) Rheology results showing the effect of cell inclusion on gel properties. Alizarin red staining of 3D cell culture within (c) pPA, (d) E-PA \K-PA, and (e) TCP (mean \pm SEM, $n=4$ gels per sample, one-way analysis of variance (ANOVA) $* P<0.05$, $* * * P<0.0001$ ).

triggered significant mineral deposition by day 12 (Figure 5c,d, Supporting Information, Figure S17).

The expression levels of osteoblast-specific genes (Runx2, Col-I, and Osp) were also studied. Osteopontin (Osp) was analyzed as a late osteoblast marker to verify stem cell differentiation (Figure 6). On day 7, statistically significant increases in the expressions of Runx2, Col-I, and Osp were observed in rMSC samples cultured on ALP-mimetic peptide nanofiber scaffolds compared to control groups, both with and without the addition of osteogenic supplements, where osteogenic medium-containing samples exhibited an earlier onset of differentiation (Figure 6a,b). Normal culture medium supplied samples showed lower expression levels compared to osteogenic medium supported cells; however, cells cultured on ALP mimetic peptide nanofibers still showed higher expressions compared to control groups. Both day 7 and day 12 results indicate that the absence of osteogenic medium causes a delay in differentiation, but the peptide itself is nonetheless sufficient to direct stem cells into the osteogenic lineage (Figure 6a,b,d,e).

In addition to gene expression analysis, differentiation of rMSCs into the osteogenic lineage was also analyzed through the immunocytochemistry staining of dentin matrix protein-1 (DMP-1; Figure 6c-f). DMP-1, a noncollagenous acidic protein present in the mineralized matrix, has a multifunctional role $\mathrm{e}^{42-44}$ as a transcription factor and a matrix protein and is commonly used to detect the extent of cell maturation since it can be found in the nucleus, cytoplasm, or ECM, depending on the level of differentiation. DMP-1 is mainly localized in the nucleus of undifferentiated osteoblasts; however, mineralization and the release of intracellular calcium stimulate its export to the extracellular matrix during maturation. ${ }^{42}$ This property of DMP-1 allows the detection of cellular maturation during osteogenic differentiation. Protein-level DMP-1 localization analysis of rMSCs suggests that osteogenic differentiation is enhanced in the presence of pPA nanofibers, with DMP-1 mostly on cellular periphery and the extracellular matrix. Since the degree of matrix mineralization is important for the differentiation and maturation of stem cells, it is possible that the advanced differentiation stage of committed rMSCs cultured on the pPA system was triggered by the efficient and rapid catalytic behavior of pPA nanofibers. Cells cultured on uncoated tissue culture plates showed no staining on day 7 , which indicates that the ALP-mimetic peptide nanofibers induce the commitment of cells into osteogenic lineage much faster than the control system.

Osteogenic Differentiation in Three-Dimensional (3D) Culture Model. As cells in their native environment are completely surrounded by the extracellular matrix, 3D cultures elicit cell responses closer to the in vivo condition compared to two-dimensional (2D) cultures, and 3D scaffolds are efficient means of simulating the physiological environment experienced by cells. In order to better mimic the environmental conditions present during the bone regeneration process, cells were also encapsulated within the pPA gel to obtain a proof-of-concept 3D culture model, which could be advantageous for further bone graft in vivo studies. The pPA system offers a facile way to create $3 \mathrm{D}$ cell cultures, since the pPA solution turns into a gel only with addition of culture media containing cells at physiological $\mathrm{pH}$. Through this method, cells are homogeneously distributed in the gel system by diffusion and the encapsulation does not interrupt cell-to-cell interactions or the diffusion of soluble factors. SaOS-2 cells were used in this study as a model cell line for the optimization of $3 \mathrm{D}$ constructs, since these cells display a greater tendency for biomineralization and osteogenic differentiation. The viability of the cells in pPA gels were tested over 14 days of culture using this technique, and the pPA culturing method was found to support cell viability in both short and long terms. Similar to 2D culture, osteogenic differentiation of SaOS-2 cells were also enhanced within the 
3D scaffold (Figure 7, Supporting Information, Figure S19). A mixture of E-PA \K-PA was used as a control gel environment, as the $3 \mathrm{D}$ environment is quite different than $2 \mathrm{D}$, and cells grown on TCP are therefore not appropriate controls for $3 \mathrm{D}$ studies. Our investigations showed that the phosphatase mimetic peptide nanofiber gel was more efficient in inducing osteogenic differentiation than control groups. Another interesting finding was the observation that cell-embedded gels displayed slightly better equilibrium storage moduli compared to gels without cell seeding. This result suggests that cell inclusion supports gel flexibility, probably through the secretion of extracellular matrix components by the encapsulated cells (Figure 7), since 6 days is sufficient for secretion of native extracellular components. Overall, $3 \mathrm{D}$ cell culture studies demonstrated that the ALP-like pPA nanofiber system has the potential to act as a versatile bone graft that assists in the catalytic processes involved in biomineralization, and can also be used for growth factor encapsulation and diffusion to support a more efficient differentiation process, similar to native tissue.

\section{CONCLUSION}

A molecular self-assembly and artificial hydrolysis strategy was used to develop multivalent and functional peptide nanofibers that can act as enzymatically active scaffolds for the enhancement of bone deposition and osteogenic differentiation. This approach allows the production of an environment that assists in bone formation through both enzymatic activity and structural support, effectively simulating two major processes involved in tissue ossification. The catalytic sites and enzymatic activity of the supramolecular nanostructures were analyzed through catalysis experiments and theoretical modeling. Effective phosphatase-like catalytic activity was demonstrated for both nanofibers in solution and nanofiber on surfaces. Imidazole moieties on peptide nanofiber scaffold were used to construct pPA nanofibers. They catalyzed bone-like mineral formation. In addition, pPA nanofibers were shown to induce in vitro osteogenic differentiation without the addition of any osteogenic support. The pPA nanofibers facilitated the rapid maturation of osteoblast-like cells and MSCs into osteoblasts, which is an important challenge faced by the currently available bone grafts. These enzyme-like, robust, versatile, and biocompatible peptide platforms can be used to develop new multifunctional biomaterials for biomedical applications.

\section{ASSOCIATED CONTENT}

\section{S Supporting Information}

Additional experimental details and results. The Supporting Information is available free of charge on the ACS Publications website at DOI: 10.1021/acs.biomac.5b00593.

\section{AUTHOR INFORMATION}

\section{Corresponding Authors}

*E-mail: moguler@unam.bilkent.edu.tr.

*E-mail: atekinay@unam.bilkent.edu.tr. Tel.: +90 312290 3552. Fax: +90312 2664365 .

\section{Notes}

The authors declare no competing financial interest.

\section{ACKNOWLEDGMENTS}

This work was funded by TUBITAK 112 T602 and TUBITAKBIDEB Ph.D. fellowship. M.O.G. and A.B.T. acknowledge support from the Turkish Academy of Sciences Distinguished Young Scientist Award (TUBA-GEBIP). Theoretical calculations were performed at TUBITAK ULAKBIM High Performance and Grid Computing Center (TRUBA Resources). We thank M. Guler for TEM imaging, and Prof. A. Dana and G. Cinar for help in Raman measurements.

\section{REFERENCES}

(1) Cao, X. Targeting osteoclast-osteoblast communication. Nat. Med. 2011, 17 (12), 1693-1693.

(2) Boonrungsiman, S.; Gentleman, E.; Carzaniga, R.; Evans, N. D.; McComb, D. W.; Porter, A. E.; Stevens, M. M. The role of intracellular calcium phosphate in osteoblast-mediated bone apatite formation. Proc. Natl. Acad. Sci. U.S.A. 2012, 109 (35), 14170-5.

(3) Mancin, F.; Scrimin, P.; Tecilla, P. Progress in artificial metallonucleases. Chem. Commun. 2012, 48 (45), 5545-59.

(4) Price, P. A.; Toroian, D.; Chan, W. S. Tissue-nonspecific alkaline phosphatase is required for the calcification of collagen in serum: A possible mechanism for biomineralization. J. Biol. Chem. 2009, 284 (7), 4594-604.

(5) Kimura, E.; Kodama, Y.; Koike, T.; Shiro, M. Phosphodiester hydrolysis by a new zinc(II) macrocyclic tetraamine complex with an alcohol pendant: Elucidation of the roles of Ser-102 and zinc(II) in alkaline phosphatase. J. Am. Chem. Soc. 1995, 117 (32), 8304-8311.

(6) O'Brien, P. J.; Herschlag, D. Alkaline phosphatase revisited: Hydrolysis of alkyl phosphates. Biochemistry 2002, 41 (9), 3207-25.

(7) Osathanon, T.; Giachelli, C. M.; Somerman, M. J. Immobilization of alkaline phosphatase on microporous nanofibrous fibrin scaffolds for bone tissue engineering. Biomaterials 2009, 30 (27), 4513-21.

(8) Gungormus, M.; Branco, M.; Fong, H.; Schneider, J. P.; Tamerler, C.; Sarikaya, M. Self assembled bi-functional peptide hydrogels with biomineralization-directing peptides. Biomaterials 2010, 31 (28), 7266-74.

(9) Spoerke, E. D.; Anthony, S. G.; Stupp, S. I. Enzyme-directed templating of artificial bone mineral. Adv. Mater. 2009, 21 (4), 425430.

(10) Suh, J.; Oh, S. Remarkable proteolytic activity of imidazoles attached to cross-linked polystyrene. J. Org. Chem. 2000, 65 (22), 7534-7540.

(11) Parkin, G. Synthetic analogues relevant to the structure and function of zinc enzymes. Chem. Rev. 2004, 104 (2), 699-767.

(12) Jencks, W. P.; Carriuolo, J. Imidazole catalysis. III. General base catalysis and the reactions of acetyl imidazole with thiols and amines. J. Biol. Chem. 1959, 234 (5), 1280-5.

(13) Guler, M. O.; Stupp, S. I. A self-assembled nanofiber catalyst for ester hydrolysis. J. Am. Chem. Soc. 2007, 129 (40), 12082-3.

(14) Chen, Z.; Xu, L.; Liang, Y.; Zhao, M. pH-sensitive water-soluble nanospheric imprinted hydrogels prepared as horseradish peroxidase mimetic enzymes. Adv. Mater. 2010, 22 (13), 1488-92.

(15) Zaramella, D.; Scrimin, P.; Prins, L. J. Self-assembly of a catalytic multivalent peptide-nanoparticle complex. J. Am. Chem. Soc. 2012, 134 (20), 8396-9.

(16) Zhao, X.; Pan, F.; Xu, H.; Yaseen, M.; Shan, H.; Hauser, C. A.; Zhang, S.; Lu, J. R. Molecular self-assembly and applications of designer peptide amphiphiles. Chem. Soc. Rev. 2010, 39 (9), 3480-98.

(17) Kokkoli, E.; Mardilovich, A.; Wedekind, A.; Rexeisen, E. L.; Garg, A.; Craig, J. A. Self-assembly and applications of biomimetic and bioactive peptide-amphiphiles. Soft Matter 2006, 2 (12), 1015-1024.

(18) Zhu, H.; Cao, B.; Zhen, Z.; Laxmi, A. A.; Li, D.; Liu, S.; Mao, C. Controlled growth and differentiation of MSCs on grooved films assembled from monodisperse biological nanofibers with genetically tunable surface chemistries. Biomaterials 2011, 32 (21), 4744-52.

(19) Stewart, J. J. P. Optimization of parameters for semiempirical methods 0.1. Method. J. Comput. Chem. 1989, 10 (2), 209-220.

(20) Roothaan, C. C. J. New developments in molecular orbital theory. Rev. Mod. Phys. 1951, 23 (2), 69-89. 
(21) Kohn, W.; Sham, L. J. Self-consistent equations including exchange and correlation effects. Phys. Rev. 1965, 140 (4A), A1133A1138.

(22) Becke, A. D. Density-functional thermochemistry 0.3 . The role of exact exchange. J. Chem. Phys. 1993, 98 (7), 5648-5652.

(23) Lee, C. T.; Yang, W. T.; Parr, R. G. Development of the ColleSalvetti correlation-energy formula into a functional of the electrondensity. Phys. Rev. B 1988, 37 (2), 785-789.

(24) Miehlich, B.; Savin, A.; Stoll, H.; Preuss, H. Results obtained with the correlation energy density functionals of becke and Lee, Yang and Parr. Chem. Phys. Lett. 1989, 157 (3), 200-206.

(25) Ditchfield, R.; Hehre, W. J.; Pople, J. A. Self-consistent molecular-orbital methods. IX. An extended Gaussian-type basis for molecular-orbital studies of organic molecules. J. Chem. Phys. 1971, 54 (2), 724-728.

(26) Byler, K. G.; Li, Y.; Houghten, R. A.; Martinez-Mayorga, K. The role of imidazole in peptide cyclization by transesterification: parallels to the catalytic triads of serine proteases. Org. Biomol. Chem. 2013, 11 (18), 2979-2987.

(27) Beertsen, W.; Vandenbos, T. Alkaline-phosphatase induces the mineralization of sheets of collagen implanted subcutaneously in the rat. J. Clin. Invest. 1992, 89 (6), 1974-1980.

(28) Hench, L. L.; Wilson, J. Surface-active biomaterials. Science 1984, 226 (4675), 630-636.

(29) Segman-Magidovich, S.; Grisaru, H.; Gitli, T.; Levi-Kalisman, Y.; Rapaport, H. Matrices of acidic $\beta$-sheet peptides as templates for calcium phosphate mineralization. Adv. Mater. 2008, 20 (11), 2156-+. (30) deAza, P. N.; Santos, C.; Pazo, A.; deAza, S.; Cusco, R.; Artus, L. Vibrational properties of calcium phosphate compounds 0.1. Raman spectrum of beta-tricalcium phosphate. Chem. Mater. 1997, 9 (4), 912-915.

(31) Ceylan, H.; Kocabey, S.; Tekinay, A. B.; Guler, M. O. Surfaceadhesive and osteogenic self-assembled peptide nanofibers for bioinspired functionalization of titanium surfaces. Soft Matter 2012, 8 (14), 3929-3937.

(32) Lee, S. S.; Huang, B. J.; Kaltz, S. R.; Sur, S.; Newcomb, C. J.; Stock, S. R.; Shah, R. N.; Stupp, S. I. Bone regeneration with low dose BMP-2 amplified by biomimetic supramolecular nanofibers within collagen scaffolds. Biomaterials 2013, 34 (2), 452-459.

(33) Arslan, E.; Garip, I. C.; Gulseren, G.; Tekinay, A. B.; Guler, M. O. Bioactive supramolecular peptide nanofibers for regenerative medicine. Adv. Healthcare Mater. 2014, 3 (9), 1357-1376.

(34) Newcomb, C. J.; Bitton, R.; Velichko, Y. S.; Snead, M. L.; Stupp, $S$. I. The role of nanoscale architecture in supramolecular templating of biomimetic hydroxyapatite mineralization. Small 2012, 8 (14), 21952202.

(35) Kocabey, S.; Ceylan, H.; Tekinay, A. B.; Guler, M. O. Glycosaminoglycan mimetic peptide nanofibers promote mineralization by osteogenic cells. Acta Biomater. 2013, 9 (11), 9075-9085.

(36) Harada, S.; Rodan, G. A. Control of osteoblast function and regulation of bone mass. Nature 2003, 423 (6937), 349-355.

(37) Komori, T. Runx2, a multifunctional transcription factor in skeletal development. J. Cell. Biochem. 2002, 87 (1), 1-8.

(38) Wojtowicz, A. M.; Templeman, K. L.; Hutmacher, D. W.; Guldberg, R. E.; Garcia, A. J. Runx2 overexpression in bone marrow stromal cells accelerates bone formation in critical-sized femoral defects. Tissue Eng., Part A 2010, 16 (9), 2795-2808.

(39) Sofia, S.; McCarthy, M. B.; Gronowicz, G.; Kaplan, D. L. Functionalized silk-based biomaterials for bone formation. J. Biomed. Mater. Res. 2001, 54 (1), 139-148.

(40) Ku, C.-H.; Pioletti, D. P.; Browne, M.; Gregson, P. J. Effect of different $\mathrm{Ti}-6 \mathrm{Al}-4 \mathrm{~V}$ surface treatments on osteoblasts behaviour. Biomaterials 2002, 23 (6), 1447-1454.

(41) Zhang, W. X.; Yang, N. L.; Shi, X. M. Regulation of mesenchymal stem cell osteogenic differentiation by glucocorticoidinduced leucine zipper (GILZ). J. Biol. Chem. 2008, 283 (8), 47234729.

(42) Narayanan, K.; Ramachandran, A.; Hao, J. J.; He, G.; Park, K. W.; Cho, M.; George, A. Dual functional roles of dentin matrix protein
1 - Implications in biomineralization and gene transcription by activation of intracellular $\mathrm{Ca}^{2+}$ store. J. Biol. Chem. 2003, 278 (19), $17500-17508$.

(43) George, A.; Sabsay, B.; Simonian, P. A. L.; Veis, A. Characterization of a novel dentin matrix acidic phosphoprotein Implications for induction of biomineralization. J. Biol. Chem. 1993, 268 (17), 12624-12630.

(44) He, G.; George, A. Dentin matrix protein 1 immobilized on type I collagen fibrils facilitates apatite deposition in vitro. J. Biol. Chem. 2004, 279 (12), 11649-11656. 